\title{
VARIABILIDADE DE ATRIBUTOS FÍSICOS E QUÍMICOS DO SOLO E PRODUÇÃO DE FEIJOEIRO CULTIVADO EM SISTEMA DE CULTIVO MINIMO COM IRRIGAÇÃO
}

\author{
Evelize Nayara Santana da Silva ${ }^{(1)}$, Rafael Montanari ${ }^{(2)^{*}}$, Alan Rodrigo Panosso(2), Adriany \\ Rodrigues Correa $^{(3)}$, Pamela Kerlyane Tomaz ${ }^{(4)}$ e Antonio Sérgio Ferraudo ${ }^{(5)}$
}

(1) Universidade Estadual de Mato Grosso do Sul, Unidade Universitária de Aquidauana, Programa de Pós-Graduação em Agronomia, Aquidauana, Mato Grosso do Sul, Brasil.

(2) Universidade Estadual Paulista, Faculdade de Engenharia, Campus de Ilha Solteira, Ilha Solteira, São Paulo, Brasil.

(3) Universidade Estadual Paulista, Faculdade de Engenharia, Campus de Ilha Solteira, Programa de Pós-Graduação em Agronomia, Ilha Solteira, São Paulo, Brasil.

(4) Universidade Estadual Paulista, Faculdade de Engenharia, Campus de Ilha Solteira, Departamento de Zootecnia, Ilha Solteira, São Paulo, Brasil.

(5) Universidade Estadual Paulista, Faculdade de Ciências Agrárias e Veterinárias, Campus de Jaboticabal, Jaboticabal, São Paulo, Brasil.

* Autor correspondente.

E-mail: montanari@agr.feis.unesp.br

\section{RESUMO}

A compreensão do potencial agrícola de um solo muitas vezes é com base apenas na interpretação por meio de análises univariadas, podendo elevar a dimensão dos problemas no momento de escolher o manejo adequado ao solo. Dessa forma, a análise multivariada surge como alternativa, pois ela é um conjunto de procedimentos que visa agrupar e discriminar grupos de indivíduos. Também, serve como instrumento de seleção de variáveis, na medida em que aquelas com maior peso na construção dos primeiros componentes principais são as possíveis que melhor representam o conjunto de dados estudados. $O$ objetivo deste trabalho foi identificar, por meio de análises multivariadas, os atributos do solo que melhor explicam a variabilidade espacial na produção da cultura do feijão. No ano agrícola de 2006/2007, no município de Selvíria, MS, foi analisada a produtividade do feijão em razão de alguns atributos físicos e químicos de um Latossolo Vermelho distroférrico, cultivado nas condições de elevado nível tecnológico de manejo pelo sistema de cultivo mínimo irrigado com pivô central. Foi demarcada a malha geoestatística para a coleta de dados do solo e da planta, com 117 pontos amostrais, numa área de $2.025 \mathrm{~m}^{2}$ e declive homogêneo de $0,055 \mathrm{~m} \mathrm{~m}^{-1}$. A 


\begin{abstract}
classificação em grupos foi feita por três métodos: método de agrupamentos hierárquico, método não hierárquico $k$-means e análise de componentes principais. Essa última análise permitiu identificar três grupos que explicam $86,3 \%$ da variabilidade total dos dados, os quais são constituídos pelos atributos físicos: densidade do solo, porosidade total, umidade gravimétrica e umidade volumétrica, que se evidenciaram com maior poder de explicação da variação da produtividade. Pode-se concluir que a análise multivariada aliada à geoestatística é importante ferramenta no auxílio ao manejo localizado.
\end{abstract}

Palavras-chave: manejo do solo, qualidade do solo, sustentabilidade agrícola.

\title{
ABSTRACT: VARIABILITY OF PHYSICAL AND CHEMICAL SOIL PROPERTIES AND PRODUCTION COMMON BEAN IN A MINIMUM TILLAGE SYSTEM WITH IRRIGATION
}

Understanding the agricultural potential of a soil is often based only on interpretation by univariate analyses, and this may increase the scale of the problems when selecting appropriate soil management practices. Thus, multivariate analysis is an alternative since it is a set of procedures aimed at grouping individuals and discriminating between these groups. It also serves as an instrument for selection of variables in that those with the highest weight in the construction of the first principal components are likely to better represent the data set under analysis. The aim of this study was to identify soil properties that best explain the spatial variability of production of common bean by means of multivariate analyses. In the 2006/2007 crop year in Selviria, MS, Brazil, we analyzed common bean yield in relation to some physical and chemical properties of an Oxisol cultivated under high technological management conditions in a minimum tillage system with center pivot irrigation. A geostatistical grid was demarcated for collection of soil and plant data, with 117 sampling points in an area of 2,025 $\mathrm{m}^{2}$ and a homogeneous slope of $0.055 \mathrm{~m} \mathrm{~m}^{-1}$. Classification into groups was carried out by three methods: the hierarchical grouping method, the non-hierarchical k-means method, and principal component analysis. We may conclude that multivariate analysis combined with precision agriculture is an important tool to assist localized management. Principal component analysis allowed us to identify three groups that explained $86.3 \%$ of the total data variability. These groups consisted of the physical properties of bulk density, total porosity, and gravimetric and volumetric moisture, which showed greater explanatory power for yield variation.

Keywords: soil management, quality of soil, agricultural sustainability.

\section{INTRODUÇÃO}

O solo é um sistema complexo, resultante da interação de fatores geológicos, topográficos e climáticos, entre outros, que juntos conferem características e propriedades químicas e físicas próprias a esse. O estudo da dependência espacial de variáveis relacionadas com a agricultura facilita a compreensão do comportamento e ocorrência dessas variáveis nas áreas agrícolas e, consequentemente, a interferência dessas na produtividade (Durigon, 2007). Por ter grande número de variáveis envolvidas, eleva-se, muitas vezes, a dimensão do problema, ao ser analisado por meio de métodos estatísticos univariados. Uma opção de análise para facilitar o trabalho com esses tipos de dados é pelo uso de análise multivariada (Silva et al., 2010).

Nesse sentido, o uso de técnicas estatísticas facilita a interpretação do comportamento dos atributos do solo, para melhor tomada de decisão na prática de manejo.
$\mathrm{Na}$ análise simultânea de muitas informações, a estatística multivariada torna-se a melhor ferramenta, possibilitando obter informações e interpretações que poderiam não ser perceptíveis com o uso da análise estatística univariada (Freitas et al., 2014). Dessa forma, alguns estudos (Baretta et al., 2008; Bognola et al., 2011; José et al., 2013; Freitas et al., 2014; Santi et al., 2012) têm aplicado técnicas multivariadas para avaliar as variáveis do solo e encontrado resultados satisfatórios.

Com essas técnicas de análise multivariada, é possível explicar o máximo de intercorrelação entre as variáveis e descobrir quais delas contribuem mais para a caracterização e, ou, alteração do solo (Pragana et al., 2012). Tais técnicas multivariadas permitem que se faça ainda redução na dimensão de análises com múltiplas respostas com o objetivo de simplificar o seu entendimento, a sua visualização e interpretação, além de obter suficientes detalhes para adequada representação desses resultados (Bognola et al., 2011). O uso de técnicas de multivariadas, associada à geoestatística, tem permitido abordagens 
eficientes em ciências agrárias, principalmente por considerar, simultaneamente, a variação espacial de um número elevado de variáveis que influenciam os sistemas de produção agrícola (Silva et al., 2010).

O Brasil é o líder mundial na produção de feijão (Phaseolus vulgaris L.); considerando as três safras anuais, estima-se que a área total de feijão deve chegar a 3,1 milhões de hectares e a produção nacional de feijão deve alcançar 2,83 milhões de toneladas na safra 2013/2014 (CONAB, 2013). A cultura do feijão constitui-se em uma das mais importantes explorações agrícolas do Brasil, não só pela área cultivada e pelo valor da produção, mas também por ser a principal fonte de proteínas para as camadas da população de menor poder aquisitivo (Soratto, 2002).

Estudos sobre o sistema radicular do feijoeiro evidenciaram que o maior percentual de raízes, 74,5 a $87,4 \%$ do total, está localizado bem próximo à superfície do solo, até $0,10 \mathrm{~m}$ de profundidade (Vilhordo et al., 1988). O crescimento do sistema radicular e da parte aérea das plantas é influenciado direta ou indiretamente por várias propriedades físicas e químicas do solo; sendo assim, a interpretação isolada de variáveis do solo e da planta pode dificultar o estabelecimento de relações funcionais do manejo do solo e o desenvolvimento e produção das culturas (Tormena, 1998).

O objetivo deste trabalho foi identificar, por meio de análises multivariadas e geoestatística, os atributos físicos e químicos do solo que melhor explicam a variabilidade espacial da cultura do feijão em um Latossolo Vermelho distroférrico, em Selvíria, MS.

\section{MATERIAL E MÉTODOS}

A área experimental foi localizada na Fazenda de Ensino, Pesquisa e Extensão da Faculdade de Engenharia de Ilha Solteira - UNESP, localizada no município de Selvíria, MS, com coordenadas de $20^{\circ} 21^{\prime}$ de latitude sul e $51^{\circ} 25^{\prime}$ de longitude oeste, com precipitação pluvial média anual de $1.300 \mathrm{~mm}$ e temperatura média de $23,7^{\circ} \mathrm{C}$. O tipo climático é Aw, segundo a classificação de Köppen, caracterizado como tropical úmido com estação chuvosa no verão e seca no inverno (Demattê, 1980). O solo da área experimental foi classificado por Demattê (1980), como sendo um Latossolo Vermelho distroférrico típico, textura muito argilosa.

Essa área vem sendo cultivada há 20 anos com a sucessão de culturas milho/feijão, semeadas, respectivamente, no verão e inverno, irrigados por um sistema de pivô central. Nos anos de 1998 e 2003, o solo foi preparado com o arado de aivecas. Contudo, nos demais anos, as culturas foram implantadas em sistema de cultivo mínimo e, especificamente, antes da semeadura deste estudo, a área foi cultivada com milho.

$\mathrm{Na}$ instalação do experimento, foi feita a escarificação na profundidade de $0,30 \mathrm{~m}$, caracterizando um sistema de cultivo mínimo. Para a semeadura do feijão, foi utilizado o cultivar Pérola, no espaçamento de 0,45 m entrelinhas, com a densidade de 300.000 plantas por hectare. $\mathrm{Na}$ condução da cultura, foram feitas as práticas de tratamento fitossanitário e o manejo químico de pragas, procedidas homogeneamente em toda a área experimental.

Foram definidas as direções $\mathrm{x}$ e $\mathrm{y}$ do sistema de coordenadas cartesianas num lançante estabelecido entre dois terraços agrícolas, onde estava semeada a cultura estudada. A malha geoestatística apresentou área de $2.025 \mathrm{~m}^{2}$, constituída de nove transeções de $40 \times 40 \mathrm{~m}$, que foram espaçadas de $5,00 \mathrm{~m}$, com pontos amostrais esquadrejados em $5 \times 5 \mathrm{~m}$, e com alguns pontos adensados de $1,67 \mathrm{~m}$ em alguns pontos de amostragem, visando detalhar o estudo da dependência espacial, totalizando 117 pontos amostrais.

As variáveis estudadas (solo e planta) foram individualmente coletadas no entorno de cada ponto amostral, que foi constituído da coleta dos dados da planta posicionada no centro e de suas circunvizinhas. Todas as análises foram efetuadas no Laboratório de Física e Química do Solo da Faculdade de Engenharia de Ilha Solteira - UNESP. Os atributos do solo foram densidade do solo (DS), densidade da partícula (DP), porosidade total (PT), resistência à penetração $(\mathrm{RP})$, umidade gravimétrica (UG), umidade volumétrica (UV), teor de matéria orgânica (MO), teor de fósforo $(\mathrm{P})$ e $\mathrm{pH}$ em $\mathrm{CaCl}_{2}$, coletados na profundidade de 0,0-0,10 m.

A densidade do solo (DS) foi determinada pelo método do anel volumétrico (Embrapa, 1997), e a da partícula (DP), pelo método do balão volumétrico (Kiehl, 1979). Dessa forma, a porosidade total do solo (PT) foi calculada de acordo com Embrapa (1997). A resistência à penetração (RP) foi avaliada com o penetrômetro de impacto (Stolf, 1991) e calculada segundo expressão contida em Rosa Filho et al. (2009). A amostra deformada do solo para definir a umidade gravimétrica (UG) foi coletada no mesmo momento que a da resistência à penetração, com um trado de caneco; e a umidade volumétrica (UV) foi determinada segundo Kiehl (1979).

O carbono orgânico (CO) foi determinado pelo método da combustão úmida, via colorimétrica, resultando no teor de matéria orgânica do solo (MO), que foi calculado de acordo com Raij et al. (1987). Já o teor de $\mathrm{P}$ foi determinado pelo método de extração com a resina trocadora de íons (Raij et al., 1987); e o $\mathrm{pH}$, potenciometricamente, em solução de $\mathrm{CaCl}_{2}$ 0,01 $\mathrm{mol} \mathrm{L}^{-1}$ (Embrapa, 1997).

Os atributos avaliados da cultura do feijoeiro foram: produtividade de grãos (PRG), com os valores 
transformados para as condições padronizadas de $0,13 \mathrm{~kg} \mathrm{~kg}^{-1}$ de umidade; número de vagens por planta (NVP); número de grãos por vagem (NGV); número de grãos por planta (NGP); e massa de 100 grãos (MCG).

Coletaram-se todas as plantas originadas do entorno do ponto amostral estaqueado aos 100 dias após a semeadura. A área representativa dessa coleta foi de $3,24 \mathrm{~m}^{2}$, com quatro linhas de plantas $(1,80 \times 1,80 \mathrm{~m})$. O material foi acondicionado em sacos de polietileno previamente identificados e em seguida as amostras foram colocadas para secagem em um terreiro sob o sol. Após a secagem, a trilha/debulha foi efetuada com o pisoteio por rodado de trator, sobre todos os sacos, devidamente amontoados em um terreiro; posteriormente, foram peneirados para separar a palhada da planta e os grãos do feijão.

Foram aplicados três métodos estatísticos multivariados, visando classificar os acessos (cada um dos 117 pontos amostrais) em grupos: análise de agrupamentos hierárquica, análise de agrupamentos não hierárquica (k-means) e análise de componentes principais (ACP). Todas as análises multivariadas foram realizadas após a padronização das variáveis em que cada uma ficou com média 0 e variância unitária (1).

Primeiramente, fez-se a ACP incluindo todas as variáveis explicativas do solo e as variáveisresposta das plantas. Esses componentes foram construídos pela combinação da correlação entre as variáveis, sendo extraídas em ordem decrescente de importância, em termos de sua contribuição para a variação total dos dados (Silva et al., 2010), utilizando-se o software Statistica. Essas correlações foram classificadas de acordo com Coelho (2003), em que o critério para classificação dos autovetores (valores que representam o peso de cada caractere, em cada componente, e variam de $-1 \mathrm{a}+1$ ) foi: valor absoluto $<0,30$, classificado como pouco significativo; 0,30-0,40, considerado mediamente significativo; $\mathrm{e} \geq 0,50$, tido como altamente significativo. As variáveis que tiveram autovetores com peso $\geq 0,50$ (altamente significativo) foram submetidas a uma nova ACP, para ranquear os componentes com maior carga fatorial (escore).

Posteriormente, os dados foram submetidos ao processamento da análise de agrupamento por método hierárquico, adotando a distância euclidiana como medida de semelhança entre as amostras e o método de Ward para discriminar a ligação de grupos. Após adotar uma quantidade de grupos que melhor caracterizava a estrutura de grupos contida nos dados originais, foi feita a análise de agrupamento por método não hierárquico, utilizando o algoritmo $k$-means (Hair Júnior et al., 2005), que permitiu caracterizar o padrão das variáveis por grupo considerado.

A geoestatística foi utilizada para quantificar a dependência espacial dos dados gerados por meio da aplicação da ACP, pelo cálculo do semivariograma experimental e pelo uso do pacote Gamma Design Software $\left(\mathrm{GS}^{+}, 2004\right)$. Os ajustes dos modelos teóricos aos semivariogramas experimentais foram efetuados prioritariamente pela seleção inicial de: menor soma dos quadrados dos desvios (SQD); maior coeficiente de determinação $\left(\mathrm{r}^{2}\right)$; maior avaliador da dependência espacial (ADE).

A decisão final do modelo que representou o ajuste foi realizada pela validação cruzada, assim como para a definição do tamanho da vizinhança, que proporcionou a melhor malha de krigagem, realizada por meio da krigagem em blocos. Para cada atributo, foram relacionados o efeito pepita (Co), o alcance (Ao) e o patamar $(\mathrm{Co}+\mathrm{C})$. A análise do avaliador da dependência espacial (ADE) foi efetuada conforme a seguinte expressão $\left(\mathrm{GS}^{+}, 2004\right)$ :

$$
\mathrm{ADE}=100 \times(\mathrm{C} /(\mathrm{C}+\mathrm{Co})
$$

em que ADE é o avaliador da dependência espacial; $\mathrm{C}$, a variância estrutural; e $\mathrm{C}+\mathrm{Co}$, o patamar.

A interpretação proposta para o $\mathrm{ADE}$ foi a seguinte: $\mathrm{ADE} \leq 20 \%$ indicou atributo espacial com muito baixa dependência; $20 \%<\mathrm{ADE} \leq 40 \%$, atributo com baixa dependência; $40 \%<\mathrm{ADE} \leq 60 \%$, atributo com média dependência; $60 \%<\mathrm{ADE} \leq 80 \%$, atributo de alta dependência; e $\mathrm{ADE} \geq 80 \%$, atributo com dependência espacial muita alta, segundo Dalchiavon et al. (2012).

A técnica de krigagem ordinária foi utilizada para estimar valores nos locais não amostrados por ser um estimador linear não enviesado; a partir desses foram construídos mapas de padrões espaciais, que emprega os mesmos valores estimados por meio da técnica de krigagem para determinação e localização das isolinhas; dessa maneira, os mapas representam linhas bem definidas e embasadas em um algoritmo de regressão linear, conforme descrito por Siqueira et al. (2008).

\section{RESULTADOS E DISCUSSÃO}

$\mathrm{Na}$ análise de componentes principais a partir de todos os atributos, foram extraídos os seis primeiros componentes. De acordo com Kaiser (1958), foram consideradas somente as variáveis com autovalores acima de 1, pois são aquelas que geram componentes com quantidade relevante de informação das variáveis originais. Esses componentes de forma acumulada explicaram $74,80 \%$ da variabilidade total dos dados (Quadro 1). A partir dessa análise, foram selecionadas as variáveis DS, PT, UG e UV, NVP, NGV e NGP, que são as com escores altamente significativos ( $\geq 0,5$ em valor absoluto); e então foi feita nova análise de ACP para encontrar aquelas que melhor explicassem a variabilidade da produtividade na área estudada. 
Quadro 1. Componentes principais (CP1, CP2, CP3, CP4, CP5 E CP6) da análise multivariada entre todos os atributos avaliados de um Latossolo Vermelho distroférrico para a profundidade de 0,00-0,10 m, cultivado com milho/feijão em cultivo mínimo

\begin{tabular}{|c|c|c|c|c|c|c|}
\hline Componente principal & CP1 & CP2 & CP3 & CP4 & CP5 & CP6 \\
\hline Autovalor & 2,89 & 2,49 & 1,57 & 1,31 & 1,16 & 1,05 \\
\hline Variância explicada (\%) & 20,65 & 17,77 & 11,20 & 9,38 & 8,30 & 7,51 \\
\hline Variável & \multicolumn{6}{|c|}{ Correlação $^{(1)}$} \\
\hline Produtividade de grãos & $-0,41$ & $-0,38$ & $-0,16$ & 0,03 & $-0,20$ & $-0,24$ \\
\hline Massa de 100 grãos & 0,10 & 0,02 & $-0,15$ & 0,49 & 0,48 & $-0,37$ \\
\hline Número de vagens/planta & $-0,16$ & $-0,87^{*}$ & $-0,08$ & $-0,14$ & $-0,09$ & $-0,05$ \\
\hline Número de grãos/vagem & $-0,10$ & $-0,80^{*}$ & $-0,19$ & $-0,12$ & 0,03 & 0,02 \\
\hline Número de grãos/planta & $-0,28$ & $-0,76^{*}$ & $-0,02$ & $-0,11$ & 0,09 & $-0,17$ \\
\hline Densidade do solo & $-0,81^{*}$ & $-0,27$ & $-0,21$ & 0,33 & $-0,10$ & $-0,07$ \\
\hline Porosidade total & $0,80^{*}$ & 0,28 & 0,02 & $-0,21$ & $-0,22$ & $-0,22$ \\
\hline Umidade gravimétrica & $0,56^{*}$ & 0,01 & $-0,51^{*}$ & $-0,48$ & 0,01 & $-0,20$ \\
\hline Umidade volumétrica & $0,91^{*}$ & $-0,18$ & 0,22 & $-0,10$ & $-0,07$ & $-0,18$ \\
\hline Matéria orgânica & 0,11 & 0,12 & $-0,48$ & $-0,10$ & 0,03 & 0,15 \\
\hline $\mathrm{P}$ & 0,25 & $-0,18$ & $-0,46$ & $-0,20$ & $-0,29$ & 0,38 \\
\hline $\mathrm{pH}\left(\mathrm{CaCl}_{2}\right)$ & 0,23 & 0,23 & $-0,26$ & $-0,42$ & 0,01 & $-0,31$ \\
\hline
\end{tabular}

(1) Correlações consideradas na interpretação do componente principal.

Nesta pesquisa, os atributos de fertilidade apresentaram correlações baixas na $\mathrm{ACP}$, isso significa que esses atributos não puderam explicar a sua influência na variabilidade (Quadro 1), resultados esses também encontrados por Santi et al. (2012), trabalhando com produtividade de grãos em um Latossolo Vermelho distrófico, e Montezano et. al. (2006), os quais desenvolveram o trabalho com a cultura do milho, onde se verificou, em escala de campo, que as correlações lineares dos atributos de fertilidade com produtividade geralmente encontram-se baixas (menores que 0,50), o que impede a sua seleção para a explicação da variabilidade de produção da cultura.

$\mathrm{Na}$ ACP com as variáveis de maiores escores, foram extraídos três componentes principais que, de forma acumulada, explicam 86,3\% da variabilidade total dos dados (Quadro 2). O primeiro componente explicou $38,61 \%$ da variabilidade total dos dados da área experimental. Esse componente foi constituído pelos atributos DS, PT, UG e UV para a profundidade de 0,00-0,10 $\mathrm{m}$, onde apenas a PT se correlacionou de maneira positiva; e os demais atributos se correlacionaram negativamente. $\mathrm{O}$ segundo componente principal explicou $32,56 \%$ da variabilidade dos dados, sendo constituído pelos atributos NVP, NGV e NGP, que também apresentaram correlações negativas. Já para o terceiro componente, houve explicação de $15,13 \%$ da variabilidade, sendo o atributo UGna profundidade de $0,00-0,10 \mathrm{~m}$ o responsável por essa variabilidade.

Quadro 2. Componentes principais (CP1, CP2 e CP3) da análise multivariada da produção do feijão e de alguns atributos físicos de um Latossolo Vermelho distroférrico para a profundidade de $0,00-0,10 \mathrm{~m}$, cultivado com milho/feijão em cultivo mínimo

\begin{tabular}{lccc}
\hline Componente principal & CP1 & CP2 & CP3 \\
\hline Autovalor & 2,70 & 2,28 & 1,06 \\
Variância explicada (\%) & 38,61 & 32,56 & 15,13 \\
Variável & & Correlação(1) & $-0,07$ \\
Número de vagens/planta & $-0,06$ & $-0,92^{*}$ & $-0,85^{*}$ \\
Número de grãos/vagem & $-0,08$ & $-0,80^{*}$ & $-0,04$ \\
Número de grãos/planta & 0,06 & $-0,06$ & 0,44 \\
Densidade do solo & $-0,85^{*}$ & 0,06 & $-0,36$ \\
Porosidade total & $0,84^{*}$ & 0,18 & $-0,79^{*}$ \\
Umidade gravimétrica & $-0,58^{*}$ & 0,08 & $-0,25$ \\
Umidade volumétrica & $-0,95^{*}$ & \\
\hline
\end{tabular}

(1) Correlações consideradas na interpretação do componente principal. 
A representação gráfica biplot (entre CP1 e CP2) (Figura 1a) permitiu caracterizar as variáveis que mais discriminaram na formação dos agrupamentos 1 , 2 e 3 . Os atributos UG $(-0,58)$, UV $(-0,95)$ e DS $(-0,85)$ permitiram discriminar o agrupamento 1 , localizado à esquerda da $\mathrm{CP} 1$ (correlações negativas), enquanto no agrupamento 2 , o atributo responsável pela discriminação foi a PT $(0,84)$; e o agrupamento 3 foi caracterizado pelos atributos NGV $(-0,85), \operatorname{NVP}(-0,92)$ e NGP $(-0,80)$. Assim, o agrupamento 1 apresentou os maiores valores de UG, UV e DS; enquanto o agrupamento 2 , caracterizou-se pelos maiores valores de PT. Já o agrupamento 3 foi caracterizado pelos maiores valores de NGV, NVP e NGP.

$\mathrm{Na}$ figura $1 b$, pode-se visualizar o posicionamento dos agrupamentos no campo experimental. Observouse que o agrupamento 3 (correspondendo a $40 \%$ da área total), em sua maioria, é situado na região sul do mapa. Esse agrupamento representou os maiores valores dos componentes de produção de feijão (NVP, NGV e NGP); essa região coincide com a região de maior produtividade de grãos de feijão como pode ser observado na figura 2 d. Já o agrupamento 2 (correspondendo a $38 \%$ da área total), estando sua maioria situada na região norte do mapa, representou os menores valores dos componentes de produção de feijão (NVP, NGV e NGP), coincidindo também com a região de menor produtividade de grãos de feijão (Figura 2d).

O dendrograma obtido pela análise de agrupamentos hierárquica é apresentado na figura 3 , em que a variação expressiva nos valores de distância euclidiana entre os acessos, para o conjunto de variáveis consideradas, torna possível fazer uma divisão de grupos. A variação encontrada neste trabalho foi de 22,5 para 40 e permitiu uma divisão exata dos acessos em três grupos. Para a confirmação da ordenação obtida na análise de agrupamentos hierárquica, aplicou-se o método de agrupamentos não hierárquico. Os resultados confirmaram a ordenação e, ainda, conforme análise de variância, todas as variáveis foram importantes para essa ordenação $(\mathrm{p}<0,01)$ (Quadro 3).

Essa divisão em grupos apresentada na figura 3 evidencia um resultado muito importante, em que pode se observar que a ordenação dos acessos ocorreu em razão dos componentes produtivos do feijão. No agrupamento 1, ficaram os acessos que possuíam os valores intermediários dos componentes produtivos do feijão (NVP, NGV e NGP); no 2, os com menores valores dos componentes produtivos; e no 3 , os com maiores valores dos componentes produtivos.

Em relação às médias dos atributos físicos (Quadro 3), verificou-se que o solo apresentou nos agrupamentos 2 e 3 valores de DS de 1,22 e $1,23 \mathrm{~kg} \mathrm{dm}^{-3}$, respectivamente, valores esses abaixo do crítico para solos argilosos (Arshad et al., 1996), que afirma que o valor crítico situa-se em torno de $1,40 \mathrm{~kg} \mathrm{dm}^{-3}$, valor esse semelhante ao encontrado no agrupamento $1\left(1,40 \mathrm{~kg} \mathrm{dm}^{-3}\right)$, que poderia dificultar o desenvolvimento radicular. Nos agrupamentos 2 e 3, a PT encontrava-se próxima à ideal, em que o solo ideal para a produção agrícola deve apresentar PT próxima a $0,50 \mathrm{~m}^{3} \mathrm{~m}^{-3}$ (Kiehl, 1979); já no agrupamento 1, essa se encontra com valores inferiores $\left(0,37 \mathrm{~m}^{3} \mathrm{~m}^{-3}\right)$.

$\mathrm{Na}$ figura 4, são apresentadas as médias padronizadas dos componentes produtivos do feijão e dos atributos físicos do solo para cada grupo, segundo análise de agrupamentos não hierárquica $k$-means. Observou-se que, na condição de alta DS, ocorreram os menores valores de PT e os maiores valores de UG e UV em relação às outras condições. Dados esses que corroboram os de Schaffrath et al. (2008),
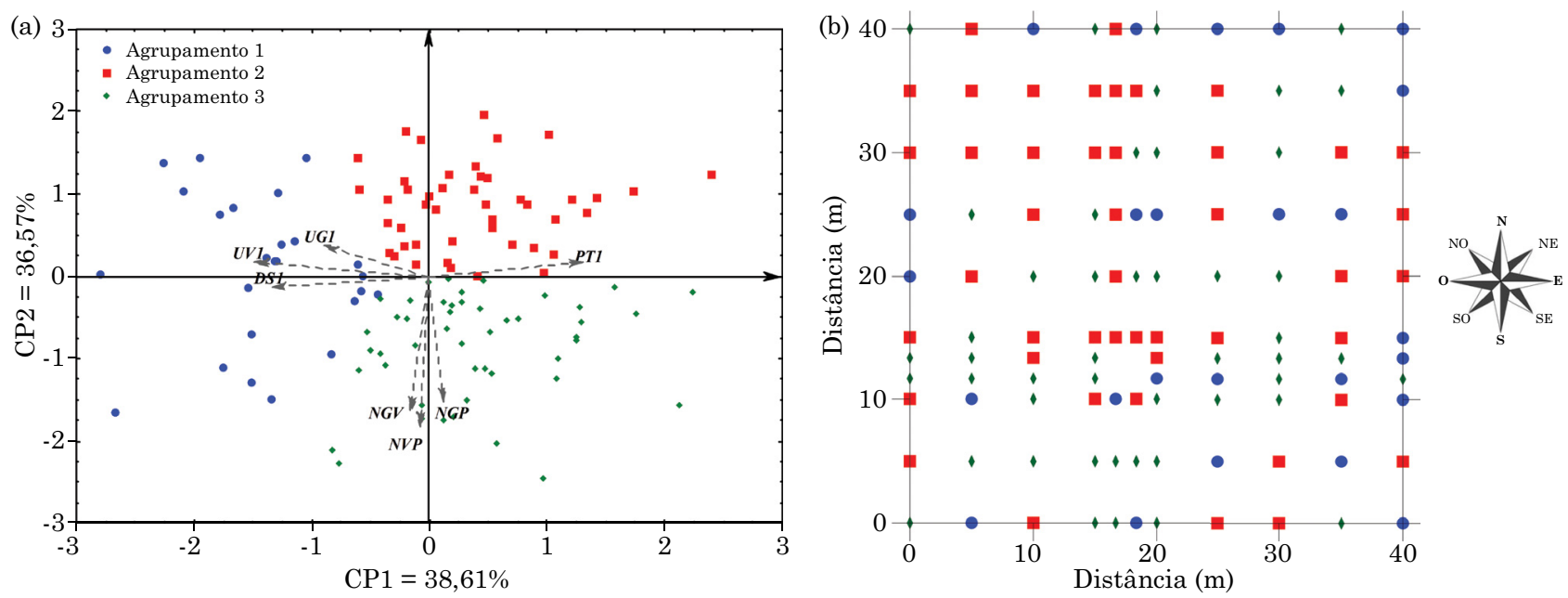

Figura 1. Dispersão (gráfico biplot) (a) e distribuição espacial dos grupos gerados (b) dos componentes da produção do feijão e de alguns atributos físicos de um Latossolo Vermelho distroférrico para a profundidade de $0,00-0,10 \mathrm{~m}$, cultivado com milho/feijão em cultivo mínimo. 
(a)

CP1

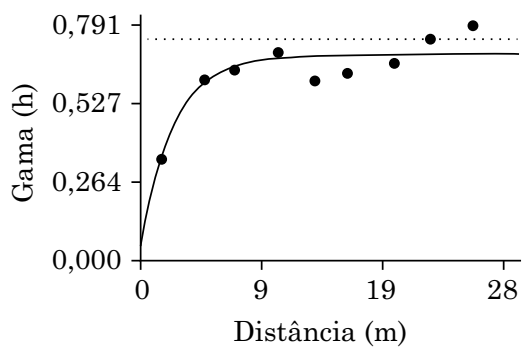

(c)

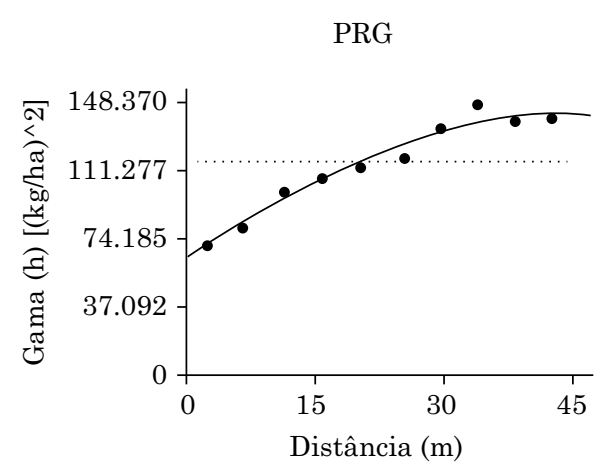

(b)

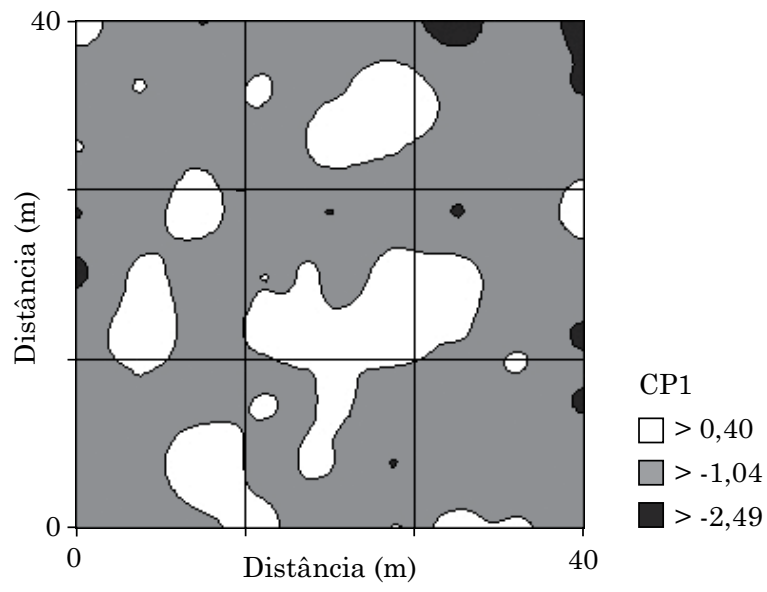

(d)

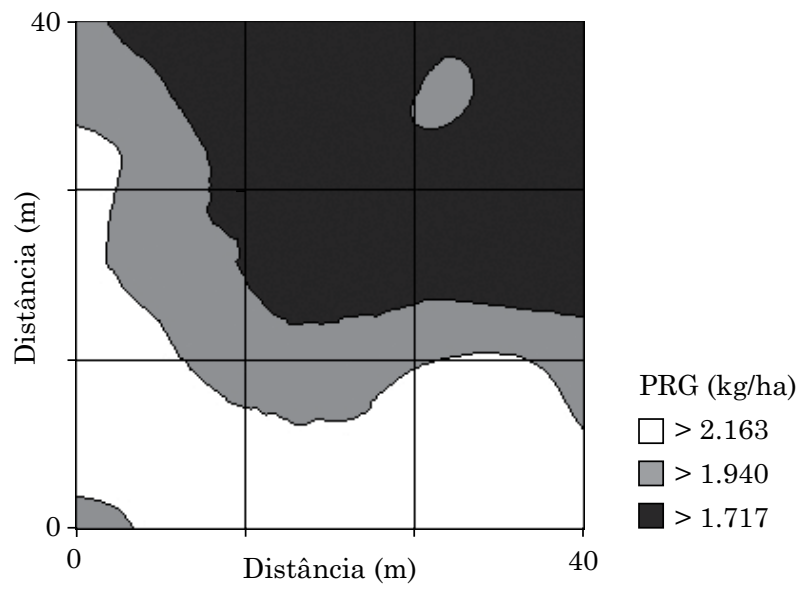

Figura 2. Semivariogramas e mapas de krigagem do componente principal 1 (CP1) e da produtividade de grãos de feijão (PRG).

os quais trabalhando também com um Latossolo Vermelho distroférrico, em plantio convencional, encontrou correlação negativa entre a DS e PT. De Maria et al. (1999) também encontraram uma correlação positiva entre a DS e a umidade do solo trabalhando em um Latossolo Vermelho. Já para as condições de menores DS (Agrupamento 2 e 3), observou-se um comportamento oposto, em que houve aumento da PT e redução da UG e UV em relação à outra condição. O comportamento das variáveis físicas estudadas não foi suficiente para explicar a variabilidade da produtividade na área, uma vez que as áreas com as maiores e menores produtividades (Agrupamento 2 e 3) apresentam comportamento semelhante em relação às variáveis físicas (Figura 4).

A análise geoestatística foi realizada com o intuito de mapear os atributos do solo e os componentes de produção do feijão, dos valores do primeiro, segundo e terceiro componentes principais, e também valores da produtividade, sendo as estimativas dos parâmetros dos modelos apresentados (Quadro 4).
Os atributos CP1 e PRG apresentaram dependência espacial entre média (PRG; e $\mathrm{ADE}=54,1 \%)$ e muito alta (CP1; e ADE = 96,0 \%) (Quadro 4), cujos modelos de semivariogramas foram do tipo esférico e exponencial, respectivamente. Já aqueles restantes (CP2 e CP3) evidenciaram efeito pepita puro. Uma vez que a CP2 é caracterizada pelos componentes de produção do feijão (NVP, NGV e NGP), que apresentam grandes variações, a distância máxima entre pontos utilizados para indicar dependência espacial pode ter sido insuficiente, originando efeito pepita puro. No tocante ao desempenho dos semivariogramas, a relação decrescente deles, analisada pela grandeza do coeficiente de determinação espacial $\left(r^{2}\right)$, foi a seguinte: PRG (0,960); e CP1 (0,808).

Freitas et al. (2014), estudando análise multivariada na avaliação de atributos de solos com diferentes texturas cultivados com cana-de-açúcar, observaram que as técnicas de análises multivariadas evidenciaram que os principais atributos para distinção dos ambientes são a densidade do solo, 


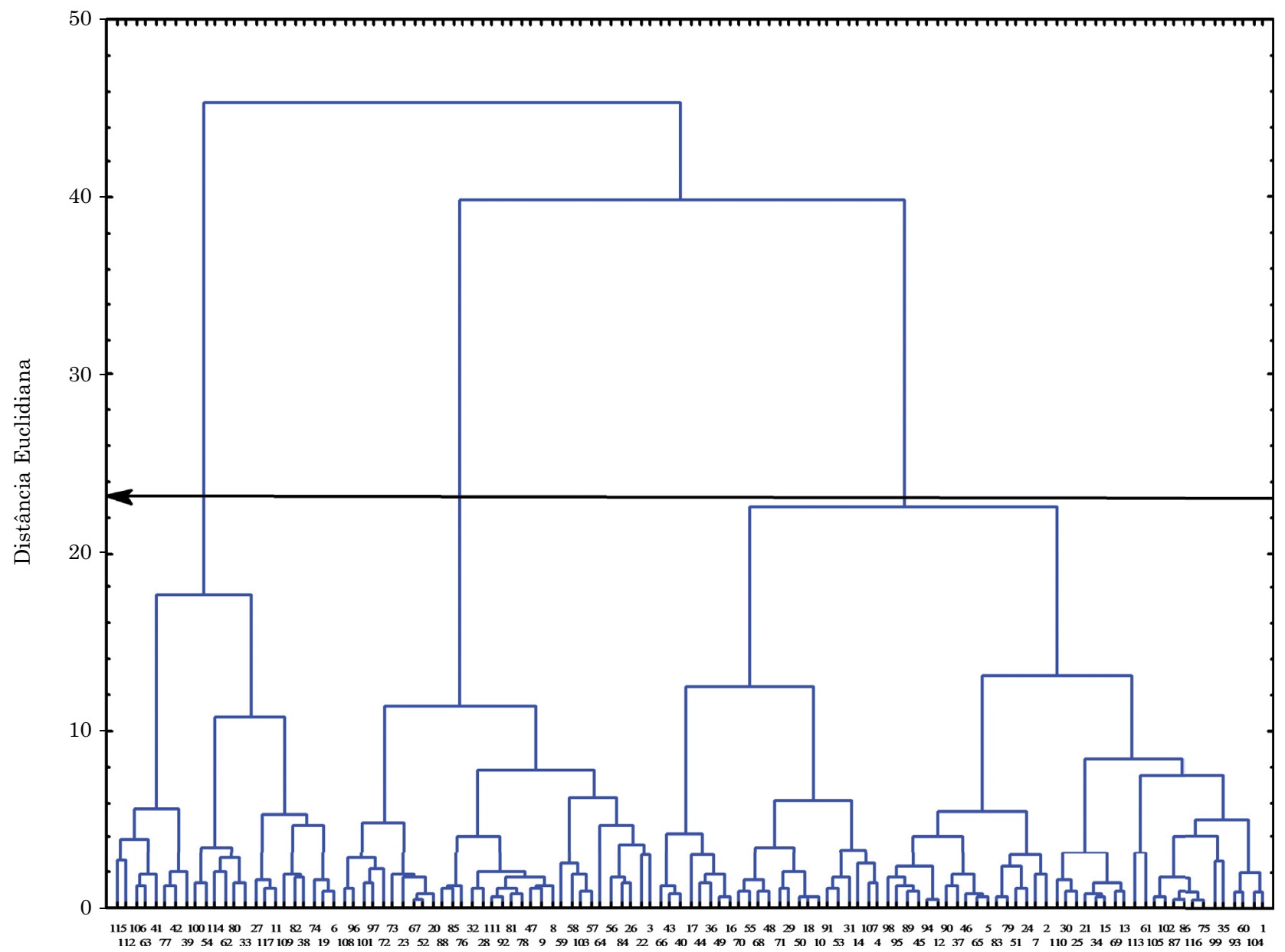

Figura 3. Dendrograma resultante da análise hierárquica de agrupamentos evidenciando a formação de grupos, segundo o número de vagens por planta, o número de grãos por vagem, o número de grãos por planta, a densidade do solo, a porosidade total, a umidade gravimétrica e a volumétrica.

a macro e a microporosidade, o manganês, o cobre e o magnésio, corroborando assim com os resultados encontrados neste trabalho, em que os principais atributos que caracterizaram a variabilidade da produtividade do feijão foram DS, PT, UG e UV. Nesse sentido, solos com menores densidades apresentam aumento da PT, aumento da permeabilidade e da infiltração de água, quebra dos agregados e aumento da resistência mecânica à penetração, elevando assim a qualidade física do solo (Pezarico et al., 2013).

Em relação aos coeficientes de determinação espacial (PRG e CP1), a PRG $\left(r^{2}=0,960\right)$ ficou na mesma ordem de grandeza daquele de

Quadro 3. Médias dos atributos de planta (NVP, NGV e NGP) e solo (DS, PT, UG e UV) dos grupos formados pela análise não hierárquica de agrupamentos $k$-means

\begin{tabular}{lccccccc}
\hline Grupo & NVP & NGV & NGP & DS & PT & UG & UV \\
\hline & & & & $\mathrm{kg} \mathrm{dm}^{-3}$ & $\mathrm{~m}^{3} \mathrm{~m}^{-3}$ & $\mathrm{~kg} \mathrm{~kg}^{-1}$ & $\mathrm{~m}^{3} \mathrm{~m}^{-3}$ \\
1 & 10,26 & 5,93 & 48,33 & 1,40 & 0,37 & 0,23 & 0,32 \\
2 & 8,50 & 5,33 & 40,89 & 1,22 & 0,45 & 0,20 & 0,25 \\
3 & 11,65 & 6,42 & 58,22 & 1,23 & 0,45 & 0,20 & 0,24 \\
Média geral & 10,14 & 5,89 & 49,44 & 1,26 & 0,43 & 0,21 & 0,26 \\
F & $47,58^{* *}$ & $44,07^{* *}$ & $40,82^{* *}$ & $25,74^{* *}$ & $29,76^{* *}$ & $24,60^{* *}$ & $75,64^{* *}$ \\
\hline
\end{tabular}

**: diferença significativa a 0,01 \%; NVP: número de vagens por planta; NGV: número de grãos por vagem; NGP: número de grãos por planta; DS: densidade do solo; PT: porosidade total; UG: umidade gravimétrica; e UV: umidade volumétrica. 
Quadro 4. Parâmetros dos semivariogramas ajustados para os componentes principais 1,2 e 3 e para a produtividade de grãos de feijão (PRG)

\begin{tabular}{|c|c|c|c|c|c|c|c|c|c|c|}
\hline \multirow{2}{*}{ Atributo $^{(1)}$} & \multirow{2}{*}{ Modelo $^{(2)}$ Efeito pepita $\left(C_{0}\right)$} & \multirow{2}{*}{ Patamar $\left(\mathrm{C}_{0}+\mathrm{C}\right)$} & \multirow{2}{*}{ Alcance $\left(\mathrm{A}_{0}\right)$} & \multirow{2}{*}{$\mathbf{r}^{2}$} & \multirow{2}{*}{$\mathrm{SQR}^{(3)}$} & \multicolumn{2}{|c|}{$\mathrm{ADE}^{(4)}$} & \multicolumn{3}{|c|}{ Validação cruzada } \\
\hline & & & & & & $\%$ & Classe & $\mathbf{a}$ & $\mathbf{b}$ & $\mathbf{r}$ \\
\hline
\end{tabular}

$\mathrm{m}$

$\boldsymbol{\gamma ( h )}$ simples dos atributos do solo

\begin{tabular}{|c|c|c|c|c|c|c|c|c|c|c|c|}
\hline $\mathrm{CP} 1$ & exp. (58) & $2,800 \times 10^{-2}$ & $6,930 \times 10^{-1}$ & 7,70 & 0,808 & $2,470 \times 10^{-2}$ & 96,0 & MA & $-0,010$ & 0,524 & 0,187 \\
\hline CP2 & epp. & 1,022 & 1,022 & - & - & - & - & - & - & - & - \\
\hline CP3 & epp. & $9,974 \times 10^{-1}$ & $9,974 \times 10^{-1}$ & - & - & - & - & - & - & - & - \\
\hline PRG $\left(\mathrm{kg} \mathrm{ha}^{-1}\right)$ & esf. (71) & $6,480 \times 10^{4}$ & $1,412 \times 10^{5}$ & 40,0 & 0,960 & $2,370 \times 10^{8}$ & 54,1 & $\mathrm{ME}$ & 50,78 & 0,974 & 0,500 \\
\hline
\end{tabular}

(1) CP1, CP2, CP3 e PRG são respectivamente os componentes principais e a produtividade de grãos de feijão; ${ }^{(2)}$ exp: exponencial; esf: esférico; epp: efeito pepita puro; número entre parênteses precedidos pelo modelo representam o número de pares no $1^{\circ}$ lag; (3) SQR: soma dos quadrados dos resíduos; ${ }^{(4)} \mathrm{ADE}$ : avaliador da dependência espacial, sendo ME: média, e MA: muito alta.

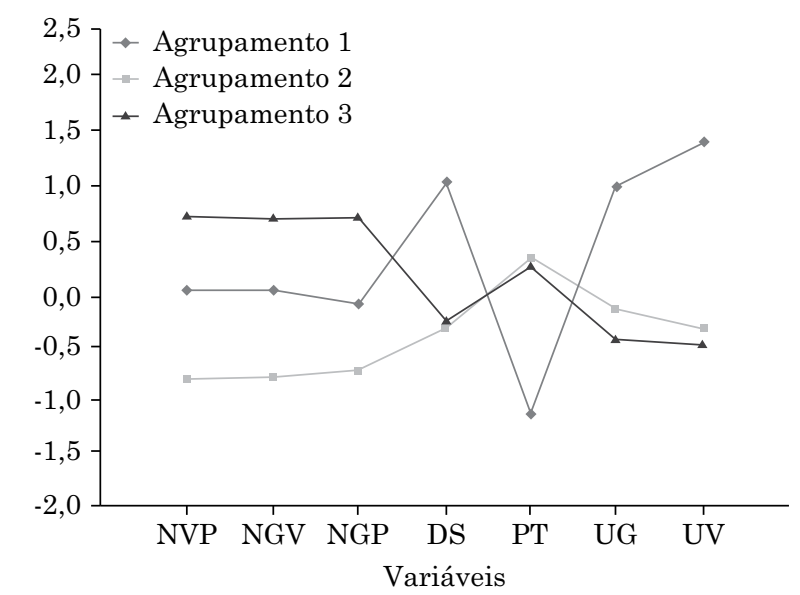

Figura 4. Médias padronizadas dos componentes da produção do feijão (NVP: número de vagens por planta, NGV: número de grãos por vagem e NGP: número de grãos por planta) e alguns atributos físicos do solo (DS: densidade do solo; PT: porosidade total; UG: umidade gravimétrica; e UV: umidade volumétrica) para cada grupo, segundo análise de agrupamentos não hierárquica $k$-means.

Santos et al. (2005), que foi de $\mathrm{r}^{2}=0,968$ e pesquisado num Latossolo Vermelho distroférrico sul-mato-grossense, com o $\mathrm{ADE}=75,5 \%$. A CP1 apresentou um $\mathrm{r}^{2}$ de 0,808 , ficando na mesma magnitude de valor que o de Silva e Lima (2012), pesquisado num Latossolo Vermelho-Amarelo, que foi de 0,880 e com o ADE de 89,0\%.

No quadro 4, a relação decrescente dos alcances da dependência espacial foi: PRG $(40,0 \mathrm{~m})$ e CP1 $(7,7 \mathrm{~m})$. Em relação ao primeiro (PRG), o alcance obtido neste trabalho foi superior ao de Santos et al. (2005), que foi de 25,9 m. Para o segundo (CP1), foi menor que o de Silva e Lima (2012), que foi $73,0 \mathrm{~m}$ e bem próximo do encontrado por José et al. (2013), o qual encontrou alcance de 8,08 para CP1. A maior continuidade espacial para PRG pode ser explicada pela figura $2 b$ e $2 d$, em que evidencia a distribuição mais homogênea da PRG no campo e variação maior na distribuição da CP1. Portanto, exclusivamente com base nesta pesquisa, assim como visando auxiliar a pesquisa futura, em que os mesmos atributos estejam envolvidos, os valores dos alcances da dependência espacial a serem utilizados nos pacotes geoestatísticos, que alimentarão os pacotes computacionais empregados na agricultura de precisão, no geral, não devem ser menores do que $7,7 \mathrm{~m}$.

O mapa do primeiro componente principal, que representou DS, PT, UG e UV, foi responsável por aproximadamente $38,61 \%$ da variabilidade contida na área. É possível perceber que, entre o quarto e oitavo nônio (Figura 2b), apresentaram-se os maiores valores; essa região é também onde se encontram as produtividades de média a alta (Figura $2 \mathrm{~d}$ ).

\section{CONCLUSÕES}

As técnicas de análise multivariada, em associação com a geoestatística, facilitaram a compreensão da variabilidade físico-química do solo.

As técnicas de análises multivariadas são eficientes para verificar as similaridades ou as diferenças na variabilidade da produtividade, com base nos atributos químicos e físicos do solo na área estudada.

A análise de componentes principais indica que entre os atributos do solo avaliados, aqueles que melhor explicam a variabilidade espacial na produção da cultura do feijão, para a área do estudo, são os físicos, como densidade do solo, porosidade total, umidade gravimétrica e volumétrica, onde os atributos densidade do solo, porosidade total, umidade gravimétrica e umidade volumétrica, que compuseram o componente principal 1 explicou $38,6 \%$ da variabilidade. 


\section{REFERÊNCIAS}

Arshad, MA, Lowery B, Grossman, R. Physical tests for monitoring soil quality. In: Doran JW, Jones AJ, editors. Methods for assessing soil quality. Madison: Soil Science Society of America; 1996. p.1-43. (Special publication, 49).

Baretta D, Baretta CRDM, Cardoso EJBN. Análise multivariada de atributos microbiológicos e químicos do solo em florestas com Araucaria angustifolia. R Bras Ci Solo. 2008;32:out/dez. Número especial.

Bognola IA, Lingnau C, Lavoranti1 OJ, Stolle L, Higa AR, De Oliveira EB. Geoestatística integrada com estatística multivariada e geoprocessamento na definição de unidades de manejo para o Pinus taeda. In: Inamasu RY, Naime JM, Resende AV, Bassoi LH, Bernardi ACC, editores. Agricultura de precisão: Um novo olhar. São Carlos: Empresa Brasileira de Pesquisa Agropecuária; 2011. p.227-31.

Coelho AM. Agricultura de precisão: manejo da variabilidade espacial e temporal dos solos e das culturas. In: Curi N, Marques JJ, Guilherme LRG, Lima JM, Lopes AS, Alvarez V VH, editores. Tópicos em ciência do solo. Viçosa, MG: Sociedade Brasileira de Ciência do Solo; 2003. p.259-90.

Companhia Nacional de Abastecimento - Conab. Acompanhamento de safra brasileira: grãos, safra 2012/2012, $11^{\circ}$ levantamento, agosto 2013 [acesso em set 2013]. Disponível em: http://www. conab.gov.br/OlalaCMS/uploads/arquivos/13_08_09_10_43_44_ boletim_portugues_agagos_2013_port.pdf.

Dalchiavon FC, Carvalho MP, Andreotti M, Montanari R. Variabilidade espacial de atributos da fertilidade de um Latossolo Vermelho distroférrico sob Sistema Plantio Direto. R Ci Agron. 2012;43:453-61.

De Maria IC, Castro OM, Souza Dias H. Atributos físicos do solo e crescimento radicular de soja em Latossolo Roxo sob diferentes métodos de preparo do solo. R Bras Ci Solo. 1999;23:703-9.

Demattê JLI. Levantamento detalhado de solos do "Campus Experimental de Ilha Solteira”. Piracicaba: Escola Superior de Agricultura "Luiz de Queiroz"; 1980.

Durigon R. Aplicação de técnicas de manejo localizado na cultura de arroz irrigado (Oryza sativa) [tese]. Santa Maria: Universidade Federal de Santa Maria; 2007.

Empresa Brasileira de Pesquisa Agropecuária - Embrapa. Manual de métodos de análise de solos. Rio de Janeiro: Centro Nacional de Pesquisa de Solos; 1997.

Freitas L, Casagrande JC, Oliveira IA, Campos MCC. Análise multivariada na avaliação de atributos de solos com diferentes texturas cultivados com cana-de-açúcar. R Ci Agron. 2014;57:224-33.

$\mathrm{GS}^{+}$: Geostatistics for environmental sciences. $7^{\mathrm{a}}$ ed. Michigan: Gamma Design Software; 2004. Hair Júnior JF, Anderson RE, Tatham RL, Black WC. Análise multivariada de dados. $5^{\mathrm{a}} \mathrm{ed}$. Porto Alegre: Bookman; 2005.

José JV, Rezende R, Freitas PSL, Hongyu K, Perboni A, Marques PAA, Dias CTS, Coelho RD. Análise multivariada e geoestatística de variáveis físico-hídricas de diferentes solos. Water Resour Irrig Manage. 2013;2:121-9.

Kaiser HF. The varimax criterion for analytic rotation in factor analysis. Psychometrika. 1958;23:187-200.
Kiehl EJ. Manual de edafologia: Relações solo-planta. São Paulo: Agronômica Ceres; 1979.

Montezano ZF, Corazza EJ, Muraoka T. Variabilidade espacial da fertilidade do solo em área cultivada e manejada homogeneamente. R Bras Ci Solo. 2006;30:839-47.

Pezarico CR, Vitorino ACT, Mercante FM, Daniel O. Indicadores de qualidade do solo em sistemas agroflorestais. R Ci Agron. 2013;56:40-7.

Pragana RB, Ribeiro MR, Nóbrega JCA, Ribeiro Filho MR, Da Costa JA. Qualidade física de Latossolos Amarelos sob plantio direto na região do Cerrado piauiense. R Bras Ci Solo. 2012;36:1591-600.

Raij B, Cantarella H, Ferreira ME, Lopes AS, Bataglia OC. Análise química do solo para fins de fertilidade. Campinas: Fundação Cargill; 1987.

Rosa Filho G, Carvalho MP, Andreotti M, Montanari R, Binotti FFS, Gioia MT. Variabilidade da produtividade da soja em função de atributos físicos de um Latossolo Vermelho distroférrico sob plantio direto. R Bras Ci Solo. 2009;33:283-93.

Santi AL, Amado TJC, Cherubin MR, Martin TN, Pires JL, Della Flora LP, Basso CJ. Análise de componentes principais de atributos químicos e físicos do solo limitantes à produtividade de grãos. Pesq Agropec Bras. 2012;47:1346-57.

Santos PA, Carvalho MP, Freddi OS, Kitamura AE, Freitag EE, Vanzela LS. Correlação linear e espacial entre o rendimento de grãos do feijoeiro e a resistência mecânica a penetração em um Latossolo Vermelho distrófico. R Bras Ci Solo. 2005;28:287-95.

Schaffrath VR, Tormena CA, Fidalski J, Gonçalves ACA. Variabilidade e correlação espacial de propriedades físicas de solo sob plantio direto e preparo convencional. R Bras Ci Solo. 2008;32:1369-77.

Silva SA, Lima JSS. Avaliação da variabilidade do estado nutricional e produtividade de café por meio da análise de componentes principais e geoestatística. R Ceres. 2012;59:271-7.

Silva SA, Lima JSS, Xavier AC, Teixeira MM. Variabilidade espacial de atributos químicos de um Latossolo VermelhoAmarelo húmico cultivado com café. R Bras Ci Solo. 2010;34:15-22.

Siqueira GM, Vieira SR, Ceddia MB. Variabilidade de atributos físicos do solo determinados por métodos diversos. Bragantia. 2008;67:203-11.

Soratto RP. Resposta do feijoeiro ao preparo do solo, manejo de água e parcelamento da adubação nitrogenada [dissertação]. Ilha Solteira: Universidade Estadual Paulista; 2002.

Stolf R. Teoria e teste experimental de fórmulas de transformação dos dados de penetrômetro de impacto em resistência do solo. $\mathrm{R}$ Bras Ci Solo. 1991;15:229-35.

Tormena CA, Silva AP, Libardi PL. Caracterização do intervalo hídrico ótimo de um Latossolo Roxo sob plantio direto. R Bras Ci Solo. 1998;22:573-81.

Vilhordo BW, Burin ME, Gandolfi VH. Morfologia. In: Zimmermann MJO, Rocha M, Yamada T, editores. Cultura do feijoeiro: Fatores que afetam a produtividade. Piracicaba: Associação Brasileira para Pesquisa da Potassa e do Fosfato; 1988. p.87-123. 